\title{
Reversion to Virulence Evaluation of a $9 R$ Vaccine Strain of Salmonella enterica Serovar Gallinarum in Commercial Brown Layers
}

Author(s)
Okamoto AS1
Menconi $A^{1}$
Gonçalves GAM 1
Rocha TS 1
Andreatti Filho RF 1
Savano EN ${ }^{2}$
Sesti L*
Faculdade de Medicina Veterinária e
Zootecnia - UNESP - Campus Botucatu.
$\quad$ Botucatu, SP, Brazil.
Ceva Campinas Ltda. Campinas, SP, Brazil.
3 Ceva Saúde Animal Ltda. Paulínia, SP, Brazil.

\section{Mail Address}
Dr. Luiz Sesti
Méd. Vet., MSc, PhD
CEVA Saúde Animal Ltda.
Rua Manuel Joaquim Filho 303
Bairro Santa Terezinha
13140-000,. Paulínia, SP, Brazil.
Phone: +551938337700
Fax: $\quad+551938337722$
E-mail: luiz.sesti@ceva.com

\section{Keywords}

9R strain, fowl typhoid, reversion to virulence, Salmonella Gallinarum, SG9R vaccine.

\section{ABSTRACT}

The live vaccine Cevac S. Gallinarum, made from a rough strain of Salmonella enterica subspecies enterica serotype Gallinarum is used for preventing fowl typhoid, a disease that still causes considerable economic losses in countries with a developing poultry industry. The objective of this paper was to evaluate a possible reversion to virulence of the strain used in a vaccine in commercial brown layers. Only Salmonella-free chicks were utilized. One hundred twenty (120) 12day-old Dekalb brown layers divided in two trials were used. The first trial had six groups of 15 birds each. Birds of group 1 were vaccinated with 10 doses of Cevac S. Gallinarum subcutaneously and 10 doses orally, in a total of 20 doses of vaccine. Then the birds of groups 2, 3, 4, and 5 received inocula that contained feces and a pool of organs with fragments of liver, heart, spleen, and cecal tonsils obtained from the immediately previous group. The second trial had three groups with 10 birds each. Birds in group 7 received inocula containing a pool of organs from birds of group 5 from trial 1, whilst the birds in group 8 were vaccinated subcutaneously with one dose of vaccine. Both trials included negative control groups (6 and 9). Throughout the experimental period, birds were monitored for reactions to the vaccination on the site of administration, clinical signs, and post-mortem lesions. In each passage, in addition to the birds euthanized to provide the inocula material, two birds from each group were euthanized for assessment of possible lesions, and their organs (liver, heart, spleen and cecal tonsils) were cultured in an attempt to isolate the vaccine strain. Except for one bird from group 1, that had a local reaction on the site of vaccination - a small vesicle with less that $0.5 \mathrm{~mm}$ that persisted until the third day post vaccination -, no other bird had any local reaction to the vaccine or any visible clinical alteration. Birds in group 8 did not present any reaction or clinical alteration because of the vaccine. We only managed to re-isolate the vaccine strain in the inocula made from organs of birds in group 1. We confirmed the isolation by means of biochemical tests, serology, and acriflavine agglutination test. All other cultures made from organs or feces, from all the other experimental groups did not show any growth of the vaccine strain or any other Salmonella serovar, suggesting that the vaccinated birds did not shed the SG9R vaccine strain. No bird presented any clinical symptoms or died during the trials, and no gross lesions were observed in the post-mortem examinations. Under the controlled conditions and time-frame of the present experiment, it was possible to conclude that the rough 9R strain of Salmonella Gallinarum present in the vaccine Cevac S. Gallinarum (Ceva Campinas Ltda. Campinas, SP - Brazil) did not revert to virulence. 
Okamoto AS, Menconi A, Gonçalves GAM, Rocha TS, Andreatti Filho RF, Savano EN, Sesti L

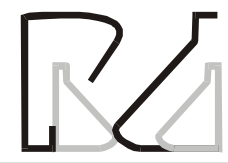

\section{INTRODUCTION}

With the growth of the poultry industry, avian salmonellosis became a limiting factor in poultry farms, in which can cause significant economic losses in all stages of production. Avian salmonellosis is the term that designates a large group of acute or chronic bird diseases caused by one or more bacteria of the genus Salmonella (Gast, 1997). These bacteria are rods from the Enterobacteriacea family, and most of them are mobile. They are aerobic or facultative anaerobic organisms that ferment sugars, producing gas and $\mathrm{H}_{2} \mathrm{~S}$, and that have a complex antigenic structure (somatic "O", flagellar "H", and capsular "K" antigens) (Gast, 1997; Barrow, 2000).

Fowl typhoid is a disease caused by Salmonella enterica subspecies enterica serotype Gallinarum, characterized by septicemia and toxemia. It is more commonly observed in adult commercial layers, but it can also affect breeders (Berchieri Júnior \& Oliveira, 2007). The infection causes high morbidity and up to $60 \%$ mortality in experimentally-infected birds (Jones et al., 2001). It has a worldwide distribution and, although it is strictly controlled in European countries and in North America, it is still present in countries with a developing poultry industry and in those where poultry are reared in back yards. In Brazil, attention was drawn to the disease due to the 80 's and 90's outbreaks, representing up to $65 \%$ of the total isolates of Salmonella spp. (Berchieri Júnior \& Oliveira, 2007).

Live vaccines against fowl typhoid are available in the market. They are made from rough $9 R$ strains originated from attenuated $9 \mathrm{~S}$ strains of Salmonella Gallinarum (Gordon et al., 1959). This kind of vaccine produces better immunological results and offers better protection to birds as compared to inactivated vaccines (Gast et al., 1993). It also induces immune responses without causing severe damage to the birds, although there are reports that they can cause some of the clinical alterations observed in field fowl typhoid (Berchieri Júnior, 2000). In addition, it has been recently reported that the virulence (mortality rate after experimental challenge) of a laboratory freeze-dried SG strain doubled after in vivo passage in chickens (Audisio \& Terzolo, 2001). Similar to other injectable vaccines, SG9R stimulates the production of $\mathrm{lg} G$ and $\lg \mathrm{M}$, making it difficult to differentiate vaccinated from challenged birds. And, as it is a live vaccine, it may also remain in the reproductive system and be transmitted through the eggs (Bersot, 2006). Inactivated vaccines may induce effective protection against the invasion of organs by
Reversion to Virulence Evaluation of a $9 R$ Vaccine Strain of Salmonella enterica Serovar Gallinarum in Commercial Brown Layers

Salmonella, although they are not effective in controlling the colonization of the intestines by these bacteria (Nakamura et al., 1994; Lee et al., 2005).

The objective of this paper was to evaluate the possibility of reversion to virulence of the 9R Salmonella Gallinarum strain present in the commercial vaccine Cevac S. Gallinarum designed for the control of fowl typhoid and other salmonellosis cases in poultry.

\section{MATERIAL AND METHODS}

\section{Vaccine and vaccination}

A live lyophilized vaccine against Salmonella Gallinarum (Cevac S. Gallinarum, batch 003/07 and diluents 001/07, both within the shelf life recommended by the manufacturer) was used in this trial. The vaccine and diluents were produced by Ceva Campinas Ltda., located in Campinas, SP, Brazil. The vaccine contained a minimum concentration of $2 \times 10^{7}$ colony forming units (CFU)/dose. Birds of group 1 in trial 1 and group 8 in trial 2 , respectively, were vaccinated at 12 and 13 days of age, respectively, after reconstitution and homogenization of vials containing 1000 doses of vaccine with $50 \mathrm{ml}$ of diluent. Dilution was calculated to supply 10 regular doses of the vaccines in a $0.5 \mathrm{ml}$ final volume. All birds in group 1 from trial 1 were double vaccinated: $0.5 \mathrm{ml}$ subcutaneously (lower dorsal area of the neck) and $0.5 \mathrm{ml}$ orally, and therefore received the equivalent to 20 doses/bird. All birds of group 8 in trial 2 received one dose of the vaccine subcutaneously.

\section{Birds and facilities}

The experiment was conducted at the poultry house of the Department of Avian Pathology of the School of Veterinary Medicine (FMVZ), UNESP, Botucatu campus, SP, Brazil, where 200 Dekalb day-old brown layers were housed in heated wire cages and received water and non-medicated feed ad libitum. Brown layers were used because they are highly susceptible to infections by Salmonella Gallinarum (Berchieri Jr. et al., 2000; Freitas, et al., 2007). The birds were vaccinated against Marek's Disease (HVT and Rispens strains), fowlpox, and infectious bursal disease at the hatchery. In order to ascertain that the birds were free from Salmonella, immediately before housing, 40 birds were euthanized by cervical dislocation, and had their liver, heart, cecal tonsils, and yolk sac content collected and cultured specifically for Salmonella isolation as previously described (Andreatti Filho, 2007). Cloacal swabs were collected from the remaining birds and cultured for 
Okamoto AS, Menconi A, Gonçalves GAM, Rocha TS, Andreatti Filho RF, Savano EN, Sesti L
Salmonella presence using the same procedure described above. At 12 days of age another group of 40 birds was euthanized and their organs were again collected for specific Salmonella isolation culture. The remaining birds (120), which had been distributed into the experimental groups, were once again submitted to cloacal swabs for Salmonella isolation procedures. On the same day (12 days of age), blood samples were collected from all birds for serological analysis (FlockChek Salmonella Enteritidis Antibody Test Kit; Idexx Laboratories, Westbrook, Maine, USA) for the detection of Salmonella Enteritidis circulating antibodies. All procedures used for microbiological investigations followed the guidelines of the Brazilian Ministry of Agriculture, Livestock and Food Supply (MAPA - Brasil, 2003). All birds were identified with plastic numbered tags that were attached to their wings.

\section{Inocula}

Feces - During the period of 24 hours after vaccination (group 1) or administration of inocula (groups 2, 3, 4, and 5) and during the 5 following days, $7.5 \mathrm{~g}$ of feces from each group were suspended in buffered peptone water (BPW) and homogenized. The whole suspension was divided into 15 aliquots and each was orally administered to all birds of the subsequent group. Each bird received $5 \mathrm{ml}$ of the feces suspension using a graded pipette.

Pool of organs - Every day, for three consecutive days, two birds in each group were euthanized, starting 48 hours after vaccination or administration of the inocula. Fragments of liver, heart, spleen, and cecal tonsils were collected, macerated in $30 \mathrm{ml}$ BPW, and filtered. All birds of the subsequent groups received $1 \mathrm{ml}$ of the final suspension using a graded pipette.

\section{Experimental design}

Trial 1 - Twenty four hours after vaccination of the birds of group 1, feces collection started and lasted for five consecutive days. Organs collection started 48 hours after vaccination and lasted for three consecutive days. The inocula made from feces and organs of the birds of group 1 were administered to birds of group 2 during the same periods in which they were collected. This means that all birds of group 2 were inoculated 5 times with feces and three times with the pool of organs, on days 1 to 5 and 2 to 4, respectively, after the vaccination of birds of group 1 . The same procedure, collection periods, and administration of feces and pool of organs were sequentially performed
Reversion to Virulence Evaluation of a 9R Vaccine Strain of Salmonella enterica Serovar Gallinarum in Commercial Brown Layers

with groups 2, 3, 4, and 5 . The birds that remained after all collections in each of the groups were monitored for 14 days after vaccination or inoculation, and eventually euthanized to check if there were any clinical gross lesions and to collect fragments of liver, heart, spleen, and cecal tonsils, which were submitted to a specific culture for the isolation of Salmonella (Andreatti Filho, 2007).

Trial 2 - On the seventh day following the first administration of feces, 10 birds of group 5 were euthanized to check for clinical gross lesions and to collect fragments of liver, heart, spleen, and cecal tonsils. After the pool of organs was prepared (as previously described), $0.5 \mathrm{ml}$ were subcutaneously inoculated in all 10 birds of group 7 in trial 2. All birds of group 8 were vaccinated with one subcutaneous dose $(0.5 \mathrm{ml}$ on the neck) of Cevac S. Gallinarum vaccine. All birds of groups 7, 8, and 9 were clinically observed for 21 days following the vaccination or inoculation. Then they were euthanized and inspected for clinical gross lesions. Fragments of liver, heart, spleen, and cecal tonsils were collected and submitted to a specific culture for isolating Salmonella (Andreatti Filho, 2007).

Groups 6 and 9 were the negative controls in trials 1 and 2, respectively. Birds of those groups did not receive any inoculum or treatment, but they were also euthanized, sampled, and analyzed as the birds in the other experimental groups.

Figure 1 shows the experimental design scheme for both trials.

\section{Culture for the isolation of the vaccine antigen}

Aliquots of all the inocula made from feces or from the pool of organs in all passages between the experimental groups were obtained and submitted to a specific culture for the isolation of the vaccine strain or any other serovar of Salmonella. The aliquots were seeded in tubes containing $10 \mathrm{ml}$ tetrathionate broth and selenite cystine broth, and were incubated for 24 hours at $370 \mathrm{o}$. Then they were seeded on Petri dishes containing brilliant green agar and MacConkey agar, and incubated as described for the isolation of the bacteria. The enriching selective broths and the seeding on the selective agars were kept for a period of 40 hours. The colonies that were isolated from each one of the media and that had typical Salmonella characteristics were seeded on triple sugar iron agar, urea broth, and lysine iron agar. The colonies with typical characteristics on these media were 

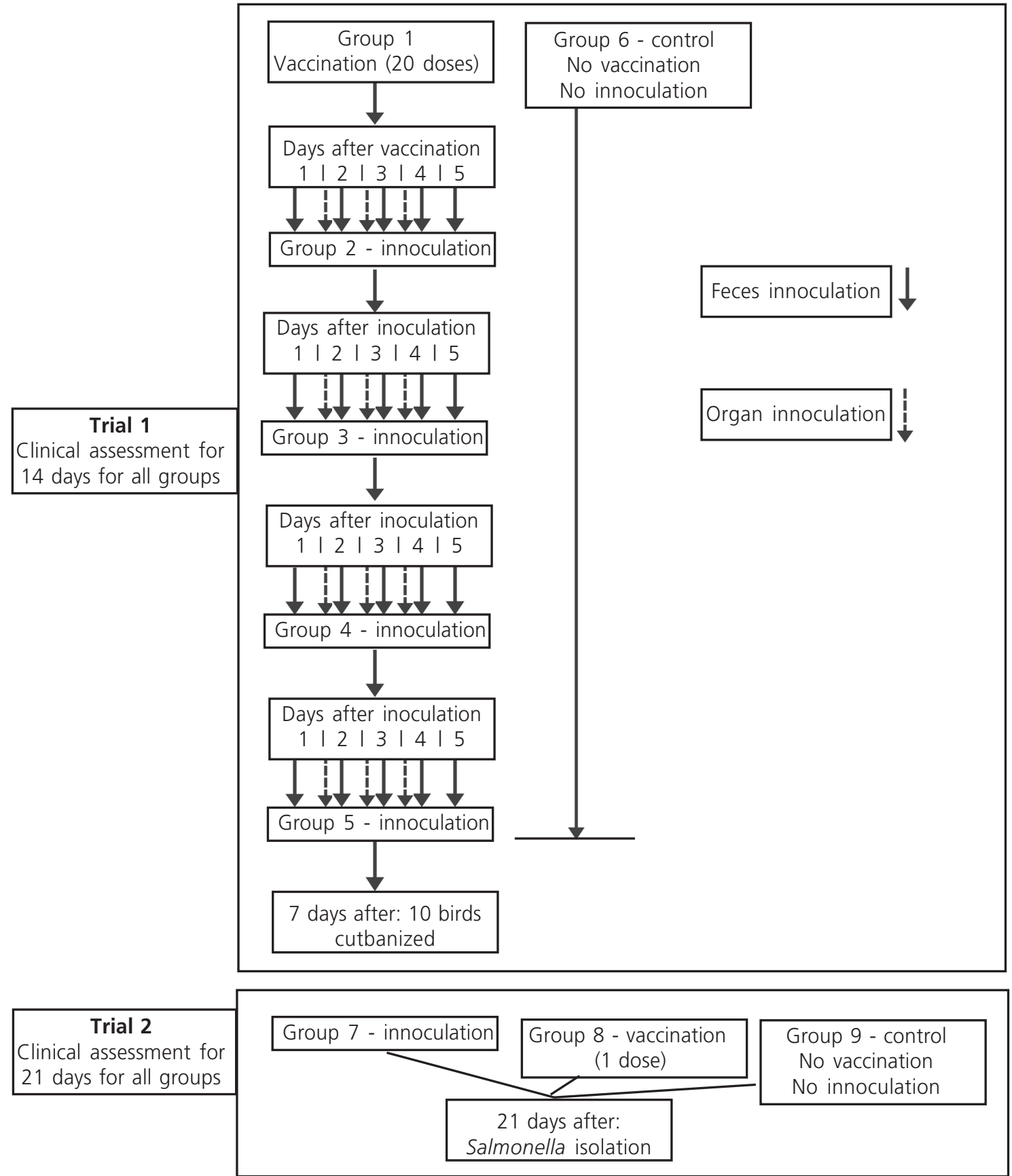

Figure 1 - Experimental design for evaluation of possible reversion to virulence of the Salmonella enterica serovar Gallinarum 9R vaccine strain present in the commercial vaccine Cevac S. Gallinarum (Ceva Campinas - Campinas, SP, Brazil).

biochemically confirmed by culture in SIM medium (sulfide, indole, and motility), Simmons citrate, methyl red, Voges-Proskauer, arginine, ornithine, malonate, glucose (gas), lactose, sucrose, mannitol, dulcitol, salicin, adonitol, inositol, sorbitol, arabinose, and raffinose. Simultaneously to the biochemical analyses, we submitted the colonies with typical Salmonella characteristics to serological tests using polyvalent somatic antiserum (Poli O), polyvalent flagellar antiserum (Poli H), and group-D somatic antiserum (factor 9) (Andreatti Filho, 2007). The 1\% acriflavine agglutination test was used to confirm the rough strain (Carter \& Subronto, 1973; MERCOSUL, 1997).

\section{RESULTS AND DISCUSSION}

The birds were monitored for local reactions to the vaccine, clinical signs of disease, and post-mortem gross 


\section{Okamoto AS, Menconi A, Gonçalves GAM, Rocha TS, Andreatti Filho RF, Savano EN, Sesti L}

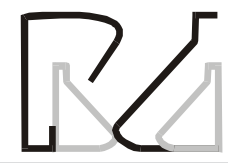

Reversion to Virulence Evaluation of a 9R Vaccine Strain of Salmonella enterica Serovar Gallinarum in Commercial Brown Layers lesions throughout the experimental period. In each of the passages between the different experimental groups, two birds from each group were euthanized to check if there were any lesions, and their organs (liver, heart, spleen, and cecal tonsils) were submitted to culture in an attempt to isolate the vaccine strain. The organs were also used to make the inocula (pool of organs and feces). We did not find any Salmonella or lesions caused by it in any of the microbiological or macroscopic analyses, respectively.

Except for one bird of group 1, which had a local reaction on the vaccination site characterized by a $<0.5 \mathrm{~mm}$ vesicle that remained visible for 3 days after vaccination, no other bird had any visible clinical alteration or local reaction, even when receiving the equivalent to 10 doses of the vaccine, subcutaneously on the neck in addition to 10 oral doses. Birds of group 8 received a single subcutaneous dose of the vaccine and did not present any local reaction or clinical alteration. These results are similar to those observed by Lee et al. (2005) when brown Hy-line layers were vaccinated subcutaneously with one or ten doses of a vaccine against fowl typhoid, at the ages of two, four, and six weeks of age. None of the birds in the present experiment had any symptoms, lesions, or mortality during the three weeks following the first vaccination. Barrow et al. (1987) reported that the use of the $9 R$ vaccine strain is effective when it is administered correctly. However, the same authors stated that the possibility of reversion to virulence is not totally clear, as the vaccine strain has the same plasmid considered essential to virulence, which is found in field virulent samples of Salmonella Gallinarum. The 9R strain of $\mathrm{S}$. Gallinarum produced hepatitis and splenic lesions without mortality in meat-type and brown-eggproducing strains of chickens, but not in Leghorns (Silva et al., 1981) and for this reason we used brown layers in the experiment. Zhang-Barber et al. (1998), using a single oral immunization with $S$. Gallinarum nuoG mutant, reduced mortality in 2-week-old chickens following challenge with virulent $S$. Gallinarum from $75 \%$ to less than $8 \%$.

The SG9R strain of the vaccine was isolated only in organs from birds of group 1 . This was confirmed by means of biochemical tests, serology, and acriflavine agglutination test. In all other cultures made from feces or organs of birds in trial 1 and 2, there was no growth of the vaccine strain or of any other Salmonella serovar, indicating that the birds vaccinated with the equivalent to 20 doses of the vaccine did not shed the vaccine SG9R strain. No bird died during the trials, and no clinical signs or gross lesions suggesting an infection by Salmonella spp. were observed in the post-mortem examinations of the birds. Wigley et al. (2005), orally inoculating three-week-old SPF white Leghorn birds with a vaccine sample of Salmonella Gallinarum at a concentration of $10^{8} \mathrm{CFU} / \mathrm{ml}$, observed gross lesions characterized by moderate to severe increase in liver and spleen size. The microbiological cultures made from the liver and spleen of those birds were positive for the same bacteria two weeks after inoculation.

The 9R strain of Salmonella Gallinarum has been used in poultry industry in several countries for many decades, and field observations and field trials results indicate that it is safe and presents reasonable effectiveness to be used as one of the tools of a comprehensive biosecurity program directed to Salmonella control in poultry farms (Barrow, 2007).

\section{CONCLUSION}

Under the controlled conditions and time-frame of the present experiment, it is possible to conclude that the rough 9R strain of Salmonella Gallinarum present in the vaccine Cevac S. Gallinarum (Ceva Campinas Ltda. Campinas, SP, Brazil) did not revert to virulence. Notwithstanding, it would be appropriate that further controlled and long-term field studies be conducted to ensure neither transmission nor acquisition of virulence plasmids between the $9 \mathrm{R}$ strain and field strains of Salmonella Gallinarum. This subject was not specifically covered in the present study.

\section{REFERENCES}

Andreatti Filho RL. Paratifo aviário. In: Andreatti Filho RL, editor. Saúde aviária e doenças. São Paulo: Editora Roca; 2007. p. 96111.

Audisio MC, Terzolo HR. Virulence analysis of a Salmonella Gallinarum strain by oral inoculation of 20-day-old chickens. Avian Diseases 2002; 46:186-191

Barrow PA. The paratyphoid Salmonellae. Revue Scientifique et Technique Office of International des Epizooties 2000; 19:351375.

Barrow PA. Salmonella infections: immune and non-immune protection with vaccines. Avian Pathology 2007; 36(1);1-13.

Barrow PA, Simpson JM, Lovell MA, Binns MM. Contribution of Salmonella gallinarum large plasmid toward virulence in fowl typhoid. Infection and Immunity 1987; 55:388-392.

Berchieri Júnior A. Salmoneloses aviárias. In: Berchieri Júnior A. 
Macari M. Doenças das aves. Campinas: Fundação APINCO de Ciência e Tecnologia Avícolas; 2000. p.185-95.

Berchieri Jr A, Oliveira GH, Pinheiro LAP, Barrow PA. Experimental Salmonella Gallinarum infection in light laying hens lines. Brazilian Journal of Microbiology 2000; 31:50-52.

Berchieri Júnior A, Oliveira GH. Tifo aviário. In: Andreatti Filho RL, editor. Saúde aviária e doenças. São Paulo: Editora Roca; 2007. p. 90-6.

Bersot LS. Salmonella no Brasil: sua importância no abate das aves. Anais do $5^{\circ}$ Simpósio de Sanidade Avícola da UFSM; 2006; Santa Maria, Rio Grande do Sul. Brasil. p. 90-4.

Brasil. Ministério da Agricultura, Pecuária e Abastecimento. Secretaria de Defesa Agropecuária. Instrução Normativa n 62 de 26 de agosto de 2003. Manual de métodos analíticos oficiais para análises microbiológicas. Diário Oficial da União,. Brasília(DF); 18 de set 2003; Seção 1:14.

Carter GR, Subronto P. Identification of type D strains of Pasteurella multocida with acriflavine. American Journal of Veterinary Research 1973; 34:293-4.

Freitas OC, Arroyave W, Alessi AC, Fagliari JJ, Berchieri Jr A. Infection of commercial laying hens with Salmonella Gallinarum: Clinical anatomopathological and haematological studies Brazilian Journal of Poultry Science, 2007, 9:133-141.

Gast RK. Paratyphoid infections. In: Calnek BW et al., editors. Diseases of poultry. 10nd ed. Ames: lowa State University Press; 1997. p. 81-121.

Gast RK, Stone HD, Holt PS. Evaluation of the efficacy of oil emulsion bacterins for reducing fecals hedding of Salmonella Enteritidis by laying hens. Avian Diseases 1993; 37:1085-91.

Gordon RF, Garside JS, Tucker JF. The use of living attenuated vaccines in the control of fowl typhoid. Veterinary Record 1959; 71:300-5.

Jones MA, Wigley P, Page KL, Hulme SD, Barrow PA. Salmonella enterica serovar Gallinarum requires the Salmonella pathogenicity island 2 type III secretion system but not the Salmonella pathogenicity island 1 type III secretion system for virulence in chickens. Infection and Immunity 2001; 69(9):5471-6.

Lee YJ, Mo IP, Kang MS. Safety and efficacy of Salmonella Gallinarum $9 R$ vaccine in young laying chickens. Avian Pathology 2005; 34(4):362-6.

Mercosul. Grupo Mercado Comum. Resolução no 04 de 01 de novembro de 1997. Regulamento técnico para a produção e o controle de vacinas, antígenos e diluentes para avicultura. Ministério da Agricultura, Pecuária e Abastecimento. Secretaria de Defesa Agropecuária. XXV GMC, Assunção, Paraguai, 25 de abril de 1997.

Nakamura MN, Nagamine T, Takahashi S, Suzuki S, Sato S. Evaluation of the efficacy of a bacterin against Salmonella enteritidis infection and the effect of stress after vaccination. Avian Diseases 1994; 38:717-24.
Silva EN, Snoeyenbos GH, Weinack OM, Smyser CF. Studies on the use of $9 R$ strain of Salmonella gallinarum as a vaccine in chickens. Avian Diseases 1981; 25:38-52.

Wigley P, Hulme S, Powers C, Beal R, Smith A, Barrow PA. Oral infection with the Salmonella enterica serovar Gallinarum 9R attenuated live vaccine as a model to characterize immunity to fowl typhoid in the chicken. Veterinary Research 2005; 1:2.

Zhang-Barber L, Turner AK, Dougan G, Barrow PA. Protection of chickens against experimental fowl typhoid using a nuoG mutant of Salmonella serotype Gallinarum. Vaccine 1998; 16:899-903. 